\title{
EVALUACIÓN DEL APRENDIZAJE: IMPLICACIONES PARA LA PRÁCTICA PEDAGÓgICA DEL PROFESOR
}

Semana Online Científica de Educação, 1a edição, de 25/10/2021 a 27/10/2021

ISBN dos Anais: 978-65-81152-18-5

BARROS; Reviu 1

\section{RESUMO}

EVALUACIÓN PRÁCTICA

\section{DEL APRENDIZAJE: PEDAGÓGICA}

IMPLICACIONES DEL
PARA LA PROFESOR

Reviu Barros[1] La práctica pedagógica es una praxis, no una técnica. E investigar sobre la práctica no es lo mismo que enseñar técnicas pedagógicas. (SARCRITÁN, 2005, p. 81).

ABSTRACTO La evaluación de los aprendizajes en el ámbito escolar es un tema que suscita constantes reflexiones en el ámbito de la investigación académica en general. Así, la práctica evaluativa genera implicaciones y desafíos que permean y son parte del trabajo del docente, requiriendo que este profesional replantee su práctica pedagógica. Este artículo tiene como objetivo reflexionar sobre las prácticas de evaluación y sus implicaciones. Comprender y verificar si las actividades planificadas y por el profesor, motivan al alumno a construir realmente un conocimiento significativo. La evaluación como recurso inseparable de la práctica pedagógica es necesaria para apoyar al docente en la conducción del proceso de aprendizaje del alumno, y corroborará el diagnóstico de lo que el alumno sabe y aprendió en las distintas estrategias de evaluación. Por tanto, la práctica de evaluar requiere que el docente domine y reflexione sobre los conocimientos, herramientas adecuadas para el uso de estrategias que incorporen el objetivo adecuado, para lograr el éxito en el proceso de enseñanza y aprendizaje de los estudiantes. En este aspecto, la escuela, como institución o comunidad social, requiere de un hilo dialógico en las relaciones entre docentes, alumnos y comunidad para vivir los procesos educativos. $\mathrm{Y}$, estas relaciones dialógicas dentro del universo educativo, ya sea formal o no formal, agregarán valores y resultarán en el comportamiento de otros individuos en términos de educación en general.

[1] Reviu Barros é professor Universitário, graduado em Letras, Pedagogia, Especialista e Mestre em Educação. Universidade - UNINTER - Curitiba, Paraná. reviub@yahoo.com.br CV: http://lattes.cnpq.br/8685651192482580 https://orcid.org/0000-0001-8322-316X

PALAVRAS-CHAVE: Docente/Alummo Evaluciación de Aprendizaje Prácticas Pedagógicas 